\title{
Acute ischaemic stroke interventions: large vessel occlusion and beyond
}

Ahmad Sweid, ${ }^{1}$ Batoul Hammoud, ${ }^{2}$ Sunidhi Ramesh, ${ }^{3}$ Daniella Wong, ${ }^{3}$ Tyler D Alexander, ${ }^{3}$ Joshua Harrison Weinberg, ${ }^{1}$ Maureen Deprince, ${ }^{1}$ Jaime Dougherty, ${ }^{1}$ Dimitri Jean-Mickael Maamari, ${ }^{4}$ Stavropoula Tjoumakaris, ${ }^{1}$ Hekmat Zarzour, ${ }^{1}$ Michael R Gooch, ${ }^{1}$ Nabeel Herial, ${ }^{1}$ Victor Romo, ${ }^{5}$ David M Hasan, ${ }^{6}$ Robert H Rosenwasser, ${ }^{1}$ Pascal Jabbour (D) ${ }^{1}$

To cite: Sweid A, Hammoud B, Ramesh S, et al. Acute ischaemic stroke interventions: large vessel occlusion and beyond. Stroke \& Vascular Neurology 2020;5: e000262. doi:10.1136/svn-2019-000262

Received 15 July 2019 Revised 29 September 2019 Accepted 13 November 2019 Published Online First 28 November 2019

\section{Check for updates}

(C) Author(s) (or their employer(s)) 2020. Re-use permitted under CC BY-NC. No commercial re-use. See rights and permissions. Published by BMJ.

${ }^{1}$ Neurosurgery, Thomas Jefferson University Hospital, Philadelphia, Pennsylvania, USA ${ }^{2}$ Endocrinology, Children's Hospital of Philadelphia, Philadelphia, Pennsylvania, USA ${ }^{3}$ Sydney Kimmel Medical College, Thomas Jefferson University, Philadelphia, Pennsylvania, USA

${ }^{4}$ School of Medicine, American University of Beirut, Beirut, Lebanon

${ }^{5}$ Anesthesia, Thomas Jefferson University - Center City Campus, Philadelphia, Pennsylvania, USA

${ }^{6}$ Neurosurgery, University of lowa Hospitals and Clinics, lowa City, lowa, USA

Correspondence to Dr Pascal Jabbour;

Pascal.jabbour@jefferson.edu

\section{ABSTRACT}

Care for acute ischaemic stroke is one of the most rapidly evolving fields due to the robust outcomes achieved by mechanical thrombectomy. Large vessel occlusion (LV0) accounts for up to $38 \%$ of acute ischaemic stroke and comes with devastating outcomes for patients, families and society in the pre-intervention era. A paradigm shift and a breakthrough brought mechanical thrombectomy back into the spotlight for acute ischaemic stroke; this was because five randomised controlled trials from several countries concluded that mechanical thrombectomy for acute stroke offered overwhelming benefits. This review article will present a comprehensive overview of LVO management, techniques and devices used, and the future of stroke therapy. In addition, we review our institution experience of mechanical thrombectomy for posterior and distal circulation occlusion.

\section{INTRODUCTION}

Care for acute ischaemic stroke is one of the most rapidly evolving fields due to the robust outcomes achieved by mechanical thrombectomy. Until the mid-1990s, little to no progress had been made in the treatment of stroke. Intravenous tissue plasminogen activator (tPA) was found to have some (but limited) benefit. ${ }^{1}$ However, due to the narrow window of treatment (that was initially 3 hours then extended to 4.5 hours) where only $3.4 \%-$ $5.2 \%$ of patients who had a stroke receive $\mathrm{tPA}^{2}$ the low rate of vessel recanalisation $(13 \%-50 \%)^{3-6}$ and the low rate of favourable outcomes $(12.9 \%-30 \%){ }^{78}$ extensive efforts have been placed to achieve outcomes similar or equivalent to the cardiac field. In 2013, three randomised controlled trials (RCTs) failed to show real benefit for catheter-based stroke interventions for large vessel occlusions (LVOs) ${ }^{9-11}$ Two years later, a paradigm shift and a breakthrough brought back mechanical thrombectomy for acute ischaemic stroke into the spotlights; this was because five RCTs from several countries concluded that mechanical thrombectomy (MT) for acute stroke offered overwhelming benefits. ${ }^{12-16}$
LVO accounts for up to $38 \%$ of acute ischaemic stroke and came with devastating outcomes for patients, families and society in the pre-intervention era. ${ }^{1718}$ Efficacy of intervention in preselected patients presenting within 24 hours has been an established treatment paradigm. ${ }^{19} 20$

\section{EPIDEMIOLOGY AND NATURAL HISTORY OF LVO}

Stroke is the second leading cause of death worldwide, with a 16 million incidence. ${ }^{21}$ The prevalence of stroke among the US population increases with age starting with $2.7 \%$ among people 20 years of age, $6 \%$ over 60 years and reaching $13 \%$ for people above 80 years. Each year, there are $\sim 800000$ new or recurrent cases of stroke. With all the advancements, $17.5 \%$ still die, making it the fifth leading cause of death in the USA. ${ }^{21}$ Patients who survive stroke may end up with long-term disability, requiring rehabilitation with an associated annual cost of more than US $\$ 40$ billion in the USA alone. ${ }^{21}$ In addition, the disability burden attributed to stroke continues to grow, with an estimated increase to 68 million disability-adjusted life years in 2020 . The incidence of LVO, as defined in the introduction, compromises $24 \%$ to $38 \%$ of acute ischaemic stroke. $^{1822}$ The proportion increases to $46 \%$ on including A2 and P2 segments. ${ }^{17}$ The estimated $10 \quad 000$ annual thrombectomies performed in recent years remains well below LVO incidence ${ }^{23}$ and suggests a potentially significant future increase in the utilisation of endovascular stroke therapies. ${ }^{24}$ Twothirds of LVO occur in the anterior circulation, mainly in the Internal Carotid Artery (ICA) and Middle Cerebral Artery, and the remaining occur in the posterior circulation with equivalent distribution among the Vertebral Artery, Basilar Arterty and Posterior Cerebral Artery. ${ }^{17}$ Tandem occlusions can occur in less than $10 \%$. $^{1725}$ 
A meta-analysis reported a double proportion of poor outcome (modified Rankin Scale (mRS) 3-6) and mortality in patients with LVO as compared with patients without LVO in the pre-endovascular era (64 vs $24 \%$, $\mathrm{p}<0.0001,26.2$ vs $1.3 \%, \mathrm{p}<0.0001$, respectively).$^{18}$ Intravenous tPA has two main limitations: it has a narrow treatment window of up to 4.5 hours since 2008 and high pharmacological resistance for more proximal occlusions (4\%-8\% for ICA vs $31 \%-44 \%$ distal recanalisation). ${ }^{3} 2627$

\section{PRE-INTERVENTION WORKFLOW}

The terms 'time is brain' and 'picture to puncture' reflect the importance of early reperfusion for clinical outcomes established by several studies. ${ }^{28-31}$ Every 30 min delay in MT decreases favourable outcomes by $11 \%,{ }^{32}$ and every 15 min acceleration at initiating tPA is associated with $4 \%$ greater odds of walking independently at discharge. ${ }^{33}$ Tremendous effort has been made by individual institutions and the healthcare system overall to overcome barriers to reduce the time for stroke treatment. ${ }^{34-36}$ Several modifiable factors have been improved and refined (such as stroke assessment tools, pre-hospital notification, communication between emergency personnel and stroke specialists, 'stroke telemedicine', mobile stroke units and direct transfer to comprehensive stroke centres), resulting in improved stroke care timing. Still, a small proportion of thrombectomy eligible patients, $27 \%$, receive a $\mathrm{MT}{ }^{23}$

Emergency medical personnel triage suspected patients who had a stroke based on the clinical examination alone. An efficient and rapid assessment has a profound influence on stroke outcomes. Multiple stroke scales have been validated for clinical use in the stroke field and have shown to speed up the triage process. The National Institutes of Health Stroke Scale (NIHSS) is complicated and time intensive (as time is often limited in field assessment); because of this, multiple alternative stroke scales exist specifically for quick field triage such as the Cincinnati Prehospital Stroke Severity Scale, the Los Angeles Motor Scale and the Rapid Arterial Occlusion Evaluation. However, a recent meta-analysis reported that the scales have a low predictive value for the presence of LVO (35\% to $50 \%) .{ }^{37}$ Another factor that reduces the time for treatment duration is a prehospital notification. The American Heart Association (AHA)/American Stroke Association (ASA) recommends pre-hospital notification of potential patients who had a stroke to the destination medical centre. ${ }^{38}$ A recent analysis showed that the prehospital notification procedure improves stroke outcome by shortening onset to needle time. ${ }^{39}$ The introduction of mobile stroke units with imaging capabilities, teleconsults with stroke specialist to assist with triaging, and potential to initiate intravenous thrombolysis tPA en route to an advanced stroke centre have been an extra step towards more prompt care and have also been shown to improve care $^{40-47}$ Finally, there has been a stance to directly transfer suspected patients with LVO to comprehensive stroke centres and bypass non-comprehensive centres to improve treatment time for patients. ${ }^{48}$ In a study, the median hospital-to-hospital distance was 14.7 miles, and median transfer time was 104 min. $^{49}$

Even hospital workflow has been adjusted for better outcomes. The change from the traditional hierarchical linear method of patient care to a single-call stroke code activation where all essential personnel are notified concurrently has been shown to reduce time to treatment in acute stroke care. ${ }^{5051}$ The Society of NeuroInterventional Surgery recommends stroke code activation, ${ }^{52}$ and similarly, the AHA urges for protocols that limit treatment delays. ${ }^{38}$

\section{MECHANICAL THROMBECTOMY}

Over the last decade, the natural history of ischaemic stroke has been dramatically improved following the five pivotal trials that set the ground for MT as the standard of care. The first attempt was in 2013, when three RCTs (Interventional Management of Stroke III (IMS III), Mechanical Retrieval and Recanalization of Stroke Clots Using Embolectomy (MR Rescue) and A Randomized Controlled Trial on Intra-arterial vs Intravenous Thrombolysis in Acute Ischemic Stroke (SYNTHESIS)) failed to exhibit the superiority of mechanical thrombectomy compared with standard medical treatment. ${ }^{9-11}$ The main limitation present within these three RCTs was the use of old thrombectomy devices and the lack of uniform protocol for confirming LVO on CT angiography, which introduced bias against endovascular therapy. ${ }^{48}$ In IMS III, $20 \%$ of patients randomised to the endovascular arm did not have a LVO. As a result, the 2013 AHA/ ASA guidelines for the early management of patients with acute ischaemic stroke advised that the "ability to improve patient outcomes has not yet been established" for thrombectomy devices. ${ }^{53}$ Two years later, The Multicenter Randomized Clinical trial of Endovascular treatment for Acute ischemic stroke in the Netherlands (MR Clean) RCT was published, showing the superiority of mechanical thrombectomy using newer thrombectomy devices compared with medically treated patients. In 2015, four other RCTs (Solitaire With the Intention For Thrombectomy as PRIMary Endovascular Treatment Trial (SWIFT PRIME), Endovascular Treatment for Small Core and Anterior Circulation Proximal Occlusion With Emphasis on Minimizing CT to Recanalization Times (ESCAPE), Randomized Trial of Revascularization With Solitaire FR Device vs Best Medical Therapy in the Treatment of Acute Stroke Due to Anterior Circulation Large Vessel Occlusion Presenting Within 8 hours of Symptom Onset (REVASCAT), and A Randomized Controlled Trial of Intra-arterial Reperfusion Therapy After Standard Dose Intravenous t-PA Within 4.5 hours of Stroke Onset Utilizing Dual Target Imaging Selection (EXTEND-IA)) that were running at the same time had to prematurely stop enrolling following MR Clean results, observing superiority of MT compared with intravenous tPA alone. ${ }^{13-16} \mathrm{~A}$ 
meta-analysis of the five trials by HERMES collaborators reported that MT for anterior circulation groups significantly reduced overall 90 -day disability, with a number needed to treat of 2.6 to reduce the mRS in one patient by at least one point. ${ }^{8}$

More recently, the Clinical Mismatch in the Triage of Wake Up and Late Presenting Strokes Undergoing Neurointervention With Trevo (DAWN) and A multicentre RCT of endovascular therapy following imaging evaluation for ischaemic stroke (DEFUSE 3) trials showed functional benefit following MT in patients presenting after 6 hours from insult. Eligible patients for MT had a mismatch on perfusion imaging. The DAWN trial showed a benefit from 6 to 24 hours, and the DEFUSE 3 showed benefit from 6 to 16 hours. ${ }^{1920}$ DEFUSE 3 found that MT along with standard medical therapy resulted in a higher percentage of functionally independent patients than standard medical treatment alone $(45 \%$ vs $17 \%) .{ }^{20}$ The CT Perfusion to Predict Response to Recanalization in Ischemic Stroke Project (CRISP) trial results are consistent with DEFUSE 3 and DAWN. Perfusion scans were used to identify patients with perfusion mismatch, and results showed that a higher rate of improvement on the NIHSS of $>8$ points was observed in subjects with a significant mismatch $(83 \%$ vs $44 \%) .{ }^{54}$ Importantly, this favourable rate of improvement remained regardless of whether patients were treated within or beyond 6 hours. Based on those five RCTs the AHA/ASA published updated guidelines in 2018, recommending that endovascular thrombectomy be considered for LVOs of the posterior circulation up to 6 hours from symptom onset and that intervention is recommended/can be considered up to 16 and 24 hours, respectively, in select patients with anterior circulation LVOs based on perfusion imaging. Also, the 2018 guidelines stress the need for perfusion scan as triaging imaging for patients presenting between 6 and 24 hours from symptom onset. ${ }^{38}$

The posterior circulation is still a grey zone, where perfusion is limited in stratifying patients that may be good candidates for mechanical intervention. Consequently, physician experience and judgement play a paramount role. ${ }^{55}$

We reviewed our cohort of mechanical thrombectomy for posterior circulation. Out of 453 thrombectomy procedures, 45 were located in the posterior circulation and were mainly a basilar artery occlusion (87\%). A solumbra technique, which is the simultaneous use of a stent retriever and aspiration catheter, was used in more than half of the procedures, and an optimal recanalisation rate (TICI $>2 \mathrm{~b}$ ) was achieved in $69 \%$. Revascularisation was achieved using a single pass in $44 \%$. When compared with the anterior circulation, posterior thrombectomy procedures were associated with a significant higher rate of extravasation ( $9 \%$ vs $4 \%, \mathrm{p}<0.01)$ and post-procedural symptomatic Intracerebral Hemorrhage $(\mathrm{ICH})(13 \%$ vs $4 \%, \mathrm{p}<0.01)$. Mortality occurred in $38 \%$, and only $20 \%$ achieved functional independence at 90 days. While the functional outcomes are lower in posterior circulation compared with the anterior circulation, the comparison should be made to tPA alone for acute basilar occlusion since the natural history of posterior circulation occlusion is worse compared with anterior circulation. ${ }^{55}$ When interpreted in this context, mechanical thrombectomy for posterior circulation results in superior outcomes.

We also reviewed our case series of distal thrombectomy procedures. The M2 was involved in $89 \%$, and $\sim 80 \%$ of thrombectomy procedures were performed using the Solumbra technique. Peri-procedural complications including distal emboli and subarachnoid hemorrhage (SAH)/ICH occurred at a rate of $7 \%$ and $8.5 \%$, respectively. Compared with proximal occlusions, distal emboli occurred at a significantly higher incidence in the distal circulation occlusions ( $7 \%$ vs $2 \%, \mathrm{p}=0.01)$. Effective recanalisation rates occurred in $89 \%$, with no difference compared with proximal circulation. Favourable outcomes occurred in $64.7 \%$, and mortality in $8 \%$.

\section{MT TECHNIQUES}

\section{Retrievable stents}

The improvements introduced to the first-generation Merci device (Concentric Medical, CA, USA) resulted in improved recanalisation rates by the second-generation devices, Solitaire (Medtronic, MN, USA) and Trevo (Stryker, MI, USA). Second-generation devices showed threefold improved recanalisation rates compared with the first-generation. ${ }^{56}$

More than $80 \%$ of enrolled patients in the five RCTs published in 2015 underwent thrombectomy using second-generation stent retrievers contrast to the Merci device used in earlier RCT resulted in superior outcomes in the endovascular arm. ${ }^{12-16}$ The safe and effective results achieved by stent retrievers led to off-label use and a push in the industry for refinements in succeeding designs. Effective recanalisation rates $(58 \%-88 \%),{ }^{12-14}$ high rates of functional independence at 3months (53\%-71\% using stent retriever vs 19\%-40\% using tPA alone), along with the low incidence of complications were achieved in the five RCTs. ${ }^{12-16}$ Such favourable results encouraged the development of novel retrievable stent designs. Both the Penumbra 3D revascularisation device (Penumbra, CA, USA) and the EmboTrap retrievable stent (Cerenovus/ Johnson \& Johnson, NJ, USA) achieved very promising effective revascularisation rates, $84 \%$ and $92.5 \%$, respectively. ${ }^{57} 58$ The off-label use of mechanical thrombectomy encompasses posterior and distal circulation. Effective recanalisation rates following posterior mechanical thrombectomy using stent retriever were reported in $90 \%$ and good functional outcomes at 3 months were achieved by $46.9 \% .^{59}$

Similarly, optimal results have been achieved with the use of stent retrievers for distal circulation occlusions, with successful reperfusion achieved in $85 \%$, favourable outcomes in $60 \%$ and symptomatic ICH at $2 \% .{ }^{60}$ 


\section{Aspiration devices}

Due to the limitations of early aspiration devices and the use of stent-retriever devices in Mr Clean, Extend IA, Escape and Swift Prime, most succeeding trials have used stent-retriever devices as the modality for thrombectomy. However, recent data suggest that aspiration provides an efficient and effective means of recanalisation in patients with LVOs. ${ }^{61-64}$

The Contact Aspiration vs Stent Retriever for Successful Revascularization study assessed outcomes in thrombectomy procedures using contact aspiration compared with stent retriever. The study concluded that outcomes were not different among both modalities; recanalisation rate (85.4\%), functional outcomes $(45.3 \%)$ and morbidity. ${ }^{61}$ Promising results pushed the envelope and paved the way for aspiration first pass technique (ADAPT). Efficacy of ADAPT has been endeavoured by the recently completed Comparison of Direct Aspiration vs Stent Retriever as a First Approach (COMPASS) trial. The investigators found no difference in functional outcomes, revascularisation rates (92\% aspiration, $89 \%$ retrievable stents) and morbidity. ${ }^{65}$ Aspiration catheters may be valuable in distal occlusion because there is no need for stent deployment, and it may be more gentle on the vessels causing fewer manipulations.

\section{Combination therapy}

Recently, thrombectomy techniques have been modified where both stent retriever and direct aspiration are used concurrently (the 'Solumbra technique') in an attempt to improve recanalisation rates. In a series from six highvolume centres, Humphries et al reported favourable outcomes following the use of the Solumbra technique for mechanical thrombectomy. The authors reported achieving $88 \%$ TICI $2 \mathrm{~b} / 3$ recanalisation and $44 \%$ favourable mRS outcomes at 90 days. ${ }^{66}$

\section{FUTURE OF STROKE THERAPY}

Technological innovations have resulted in a significant shift in patient care, two of which are worth mentioning; The volumetric impedance phase shift spectroscopy device (Cerebrotech, CA, USA) has demonstrated high sensitivity and specificity in detecting LVOs in patients who had a stroke. ${ }^{48} 67$ It is a non-invasive device that is placed on the patient's head that detects changes in bioimpedance in the brain caused by several pathologies, including ischaemia. ${ }^{48}{ }^{67}$ Another non-invasive device is the SONAS device (BURL Concepts, CA, USA) that uses transcranial ultrasound and microbubble intravenous contrast to identify potential LVOs.

Perhaps more notably, catheter advancements are occurring at a rapid pace aiming to improve manoeuvrability, efficacy and safety of the devices. The Lazarus Effect Cover (Medtronic, MN, USA) is designed to provide a protective sheath around retrievable stents to protect against distal embolisation. Once the stent engages with the clot, it is re-sheathed to prevent clot fragmentation and dislodgment. ${ }^{68}$ A small case series of 20 patients reported high rate of effective recanalisation and no evidence of distal emboli. ${ }^{69}$ Another innovative concept is the R4Q aspiration catheter (MIVI Neuroscience, MN, USA). The distal one-quarter of the catheter functions as an extension of the guide catheter, allowing the full guide catheter to be used to deliver suction. ${ }^{70}$ The future of stroke will be stem cell therapy to stimulate prompt neurological recovery.

\section{CONCLUSION}

We are in an era where the second leading cause of death in the world that carries a high burden has become a treatable disease. Huge efforts on all levels have been placed and are still laid to improve time for stroke treatment; beginning with field triage to clot retrieval and post-procedural care and rehabilitation.

\section{Twitter Pascal Jabbour @PascalJabbourMD}

Contributors All authors reviewed and agreed on the final version of the manuscript. Conception or design of the work: AS, BH, SR, JHW, PJ. Drafting the work: AS, BH, SR, DW, TDA, MD, JD, DJ-MM. Revising the work for valuable intellectual content: MRG, HZ, VR, DMH, RHR. Final approval of the version: ST, PJ.

Funding The authors have not declared a specific grant for this research from any funding agency in the public, commercial or not-for-profit sectors.

Competing interests $\mathrm{PJ}$ is a consultant for Medtronic and Micro Vention. ST is a consultant for Stryker.

Patient consent for publication Not required.

Provenance and peer review Commissioned; internally peer reviewed.

Open access This is an open access article distributed in accordance with the Creative Commons Attribution Non Commercial (CC BY-NC 4.0) license, which permits others to distribute, remix, adapt, build upon this work non-commercially, and license their derivative works on different terms, provided the original work is properly cited, appropriate credit is given, any changes made indicated, and the use is non-commercial. See: http://creativecommons.org/licenses/by-nc/4.0/.

ORCID iD

Pascal Jabbour http://orcid.org/0000-0002-8965-2413

\section{REFERENCES}

1 Hopkins LN, Beumer D, Mulder M. Blazing the frontiers of stroke therapy. Neurosurgery 2019;85:S1-2.

2 Adeoye O, Hornung R, Khatri P, et al. Recombinant tissue-type plasminogen activator use for ischemic stroke in the United States: a doubling of treatment rates over the course of 5 years. Stroke 2011;42:1952-5.

3 Saqqur M, Uchino K, Demchuk AM, et al. Site of arterial occlusion identified by transcranial Doppler predicts the response to intravenous thrombolysis for stroke. Stroke 2007;38:948-54.

4 De Silva DA, Brekenfeld C, Ebinger M, et al. The benefits of intravenous thrombolysis relate to the site of baseline arterial occlusion in the Echoplanar Imaging Thrombolytic Evaluation Trial (EPITHET). Stroke 2010;41:295-9.

5 Paciaroni M, Balucani C, Agnelli G, et al. Systemic thrombolysis in patients with acute ischemic stroke and internal carotid artery occlusion. Stroke 2012;43:125-30.

6 Jansen O, von Kummer R, Forsting M, et al. Thrombolytic therapy in acute occlusion of the intracranial internal carotid artery bifurcation. AJNR Am J Neuroradiol 1995;16:1977-86.

7 National Institute of Neurological Disorders and Stroke rt-PA Stroke Study Group. Tissue plasminogen activator for acute ischemic stroke. N Engl J Med 1995;333:1581-8.

8 Goyal M, Menon BK, van Zwam WH, et al. Endovascular thrombectomy after large-vessel ischaemic stroke: a meta-analysis of individual patient data from five randomised trials. Lancet 2016;387:1723-31. 
9 Broderick JP, Palesch YY, Demchuk AM, et al. Endovascular therapy after intravenous t-PA versus t-PA alone for stroke. $N$ Engl J Med 2013;368:893-903.

10 Ciccone A, Valvassori L, Nichelatti M, et al. Endovascular treatment for acute ischemic stroke. N Engl J Med 2013;368:904-13.

11 Kidwell CS, Jahan R, Gornbein J, et al. A trial of imaging selection and endovascular treatment for ischemic stroke. N Engl J Med 2013;368:914-23.

12 Berkhemer OA, Fransen PSS, Beumer D, et al. A randomized trial of intraarterial treatment for acute ischemic stroke. $N$ Engl J Med 2015;372:11-20.

13 Campbell BCV, Mitchell PJ, Kleinig TJ, et al. Endovascular therapy for ischemic stroke with perfusion-imaging selection. N Engl J Med 2015;372:1009-18.

14 Goyal M, Demchuk AM, Menon BK, et al. Randomized assessment of rapid endovascular treatment of ischemic stroke. $N$ Engl J Med 2015;372:1019-30.

15 Jovin TG, Chamorro A, Cobo E, et al. Thrombectomy within 8 hours after symptom onset in ischemic stroke. $N$ Engl $\mathrm{J}$ Med 2015;372:2296-306.

16 Saver JL, Goyal M, Bonafe A, et al. Stent-retriever thrombectomy after intravenous t-PA vs. t-PA alone in stroke. $N$ Engl J Med 2015;372:2285-95.

17 Smith WS, Lev MH, English JD, et al. Significance of large vessel intracranial occlusion causing acute ischemic stroke and TIA. Stroke 2009;40:3834-40.

18 Malhotra K, Gornbein J, Saver JL. Ischemic strokes due to largevessel occlusions contribute disproportionately to stroke-related dependence and death: a review. Front Neurol 2017;8:651.

19 Nogueira RG, Jadhav AP, Haussen DC, et al. Thrombectomy 6 to 24 hours after stroke with a mismatch between deficit and infarct. $N$ Engl J Med 2018;378:11-21

20 Albers GW, Marks MP, Kemp S, et al. Thrombectomy for stroke at 6 to 16 hours with selection by perfusion imaging. N Engl J Med 2018;378:708-18.

21 Benjamin EJ, Virani SS, Callaway CW, et al. Heart disease and stroke statistics - 2018 update: a report from the American Heart Association. Circulation 2018;137:e67.

22 Dozois A, Hampton L, Kingston CW, et al. PLUMBER study (prevalence of large vessel occlusion strokes in Mecklenburg County emergency response). Stroke 2017;48:3397-9.

23 Rai AT, Seldon AE, Boo S, et al. A population-based incidence of acute large vessel occlusions and thrombectomy eligible patients indicates significant potential for growth of endovascular stroke therapy in the USA. J Neurointerv Surg 2017;9:722-6.

24 Rennert RC, Wali AR, Steinberg JA, et al. Epidemiology, natural history, and clinical presentation of large vessel ischemic stroke. Neurosurgery 2019;85:S4-8.

25 Beumer D, Mulder MJHL, Saiedie G, et al. Occurrence of intracranial large vessel occlusion in consecutive, non-referred patients with acute ischemic stroke. Neurovascular Imaging 2016;2.

26 del Zoppo GJ, Poeck K, Pessin MS, et al. Recombinant tissue plasminogen activator in acute thrombotic and embolic stroke. Ann Neurol 1992;32:78-86.

27 Bhatia R, Hill MD, Shobha N, et al. Low rates of acute recanalization with intravenous recombinant tissue plasminogen activator in ischemic stroke: real-world experience and a call for action. Stroke 2010;41:2254-8.

28 C-HJ S, Nogueira RG, Glenn BA, et al. "Picture to puncture": a novel time metric to enhance outcomes in patients transferred for endovascular reperfusion in acute ischemic stroke. Circulation 2013;127:1139-48.

29 Khatri P, Yeatts SD, Mazighi M, et al. Time to angiographic reperfusion and clinical outcome after acute ischaemic stroke: an analysis of data from the Interventional Management of Stroke (IMS III) phase 3 trial. Lancet Neurol 2014;13:567-74.

30 Goyal M, Jadhav AP, Bonafe A, et al. Analysis of workflow and time to treatment and the effects on outcome in endovascular treatment of acute ischemic stroke: results from the swift prime randomized controlled trial. Radiology 2016;279:888-97.

31 Menon BK, Sajobi TT, Zhang Y, et al. Analysis of workflow and time to treatment on thrombectomy outcome in the Endovascular Treatment for Small Core and Proximal Occlusion Ischemic Stroke (ESCAPE) randomized, controlled trial. Circulation 2016;133:2279-86.

32 Shi Z-S, Liebeskind DS, Xiang B, et al. Predictors of functional dependence despite successful revascularization in large-vessel occlusion strokes. Stroke 2014;45:1977-84.

33 Katz BS, Adeoye O, Sucharew H, et al. Estimated impact of emergency medical service triage of stroke patients on comprehensive stroke centers. Stroke 2017;48:2164-70.
34 Mikulík R, Kadlecová P, Czlonkowska A, et al. Factors influencing in-hospital delay in treatment with intravenous thrombolysis. Stroke 2012;43:1578-83.

35 Leifer D, Bravata DM, Connors III J, et al. Metrics for measuring quality of care in comprehensive stroke centers: detailed followup to Brain Attack Coalition comprehensive stroke center recommendations: a statement for healthcare professionals from the American Heart Association/American Stroke Association. Stroke 2011;42:849-77.

36 Mehta BP, Leslie-Mazwi TM, Chandra RV, et al. Reducing doorto-puncture times for intra-arterial stroke therapy: a pilot quality improvement project. J Am Heart Assoc 2014;3:e000963.10.1161/ JAHA.114.000963

37 Smith EE, Kent DM, Bulsara KR, et al. Accuracy of prediction instruments for diagnosing large vessel occlusion in individuals with suspected stroke: a systematic review for the 2018 guidelines for the early management of patients with acute ischemic stroke. Stroke 2018;49:e111-22.

38 Powers WJ, Rabinstein AA, Ackerson T, et al. 2018 guidelines for the early management of patients with acute ischemic stroke: a guideline for healthcare professionals from the American Heart Association/ American Stroke Association. Stroke 2018;49:e46-99.

39 Zhang S, Zhang J, Zhang M, et al. Prehospital notification procedure improves stroke outcome by shortening onset to needle time in Chinese urban area. Aging Dis 2018;9:426.

40 Demaerschalk BM, Bobrow BJ, Raman R, et al. Stroke team remote evaluation using a digital observation camera in Arizona: the initial Mayo clinic experience trial. Stroke 2010;41:1251-8.

41 Meyer BC, Raman R, Hemmen T, et al. Efficacy of site-independent telemedicine in the stroke Doc trial: a randomised, blinded, prospective study. Lancet Neurol 2008;7:787-95.

42 Nelson RE, Saltzman GM, Skalabrin EJ, et al. The cost-effectiveness of telestroke in the treatment of acute ischemic stroke. Neurology 2011;77:1590-8.

43 Switzer JA, Demaerschalk BM, Xie J, et al. Cost-Effectiveness of hub-and-spoke TeleStroke networks for the management of acute ischemic stroke from the hospitals' perspectives. Circ Cardiovasc Qual Outcomes 2013;6:18-26.

44 Rajan SS, Rajan S, Baraniuk S, et al. Implementing a mobile stroke unit program in the United States: why, how, and how much? JAMA Neurol 2015;72:229-34.

45 Kettner M, Helwig SA, Ragoschke-Schumm A, et al. Prehospital computed tomography angiography in acute stroke management. Cerebrovasc Dis 2017;44:338-43.

46 Nyberg EM, Cox JR, Kowalski RG, et al. Mobile stroke unit reduces time to image acquisition and reporting. AJNR Am J Neuroradiol 2018;39:1293-5.

47 Parker SA, Bowry R, Wu T-C, et al. Establishing the first mobile stroke unit in the United States. Stroke 2015;46:1384-91.

48 Yaeger KA, Shoirah H, Kellner CP, et al. Emerging technologies in optimizing pre-intervention workflow for acute stroke. Neurosurgery 2019;85:S9-17.

49 Prabhakaran S, Ward E, John S, et al. Transfer delay is a major factor limiting the use of intra-arterial treatment in acute ischemic stroke. Stroke 2011;42:1626-30.

50 Fonarow GC, Smith EE, Saver JL, et al. Improving door-to-needle times in acute ischemic stroke: the design and rationale for the American Heart Association/American Stroke Association's target: stroke initiative. Stroke 2011;42:2983-9.

$51 \mathrm{Heo} \mathrm{JH}$, Kim YD, Nam HS, et al. A computerized in-hospital alert system for thrombolysis in acute stroke. Stroke 2010;41:1978-83.

52 McTaggart RA, Ansari SA, Goyal M, et al. Initial hospital management of patients with emergent large vessel occlusion (ELVO): report of the Standards and Guidelines Committee of the Society of Neurointerventional Surgery. J Neurointerv Surg 2017;9:316-23

53 Jauch EC, Saver JL, Adams Jr HP, et al. Guidelines for the early management of patients with acute ischemic stroke: a guideline for healthcare professionals from the American Heart Association/ American Stroke Association. Stroke 2013;44:870-947.

54 Lansberg MG, Christensen S, Kemp S, et al. Computed tomographic perfusion to predict response to recanalization in ischemic stroke. Ann Neurol 2017:81:849-56.

55 Munich SA, Vakharia K, Levy El. Overview of mechanical thrombectomy techniques. Neurosurgery 2019;85:S60-7.

56 Saver JL. The 2012 Feinberg Lecture: treatment swift and treatment sure. Stroke 2013;44:270-7.

57 Nogueira RG, Frei D, Kirmani JF, et al. Safety and efficacy of a 3-dimensional stent retriever with aspiration-based thrombectomy vs aspiration-based thrombectomy alone in acute ischemic stroke intervention. JAMA Neurol 2018;75:304-11. 
58 Zaidat OO, Bozorgchami H, Ribó M, et al. Primary results of the multicenter ARISE II study (Analysis of Revascularization in Ischemic Stroke with EmboTrap). Stroke 2018;49:1107-15.

59 Kang D-H, Jung C, Yoon W, et al. Endovascular thrombectomy for acute basilar artery occlusion: a multicenter retrospective observational study. J Am Heart Assoc 2018;7:e009419.

60 Coutinho JM, Liebeskind DS, Slater L-A, et al. Mechanical thrombectomy for isolated M2 occlusions: a post hoc analysis of the StAR, SWIFT, and SWIFT PRIME studies. AJNR Am J Neuroradiol 2016;37:667-72.

61 Lapergue B, Blanc R, Gory B, et al. Effect of endovascular contact aspiration vs stent retriever on revascularization in patients with acute ischemic stroke and large vessel occlusion. JAMA 2017;318:443-52.

62 Phan K, Maingard J, Kok HK, et al. Contact aspiration versus stentretriever thrombectomy for distal middle cerebral artery occlusions in acute ischemic stroke: meta-analysis. Neurointervention 2018;13:100-9

63 Turk AS, Spiotta A, Frei D, et al. Initial clinical experience with the adapt technique: a direct aspiration first pass technique for stroke thrombectomy. J Neurointerv Surg 2018;10:i20-5.
64 Turk AS, Frei D, Fiorella D, et al. ADAPT FAST study: a direct aspiration first pass technique for acute stroke thrombectomy. $J$ Neurointerv Surg 2018;10:i4-7.

65 A comparison of direct aspiration vs. stent retriever as a first approach ("COMPASS"): a randomized trial. International Stroke Conference 2018.

66 Humphries W, Hoit D, Doss VT, et al. Distal aspiration with retrievable stent assisted thrombectomy for the treatment of acute ischemic stroke. J Neurointerv Surg 2015;7:90-4.

67 Kellner CP, Sauvageau E, Snyder KV, et al. The vital study and overall pooled analysis with the VIPS non-invasive stroke detection device. $J$ Neurointerv Surg 2018;10:1079-84.

68 Mokin M, Setlur Nagesh SV, lonita CN, et al. Stent retriever thrombectomy with the cover accessory device versus proximal protection with a balloon guide catheter: in vitro stroke model comparison. J Neurointerv Surg 2016;8:413-7.

69 Piotin M, Redjem H, Ciccio G, et al. Abstract WMP2: a new device to prevent embolization in new territories during mechanical thrombectomy. Stroke 2016;47.

70 Long TD, Kallmes DF, Hanel R, et al. Novel aspiration catheter design for acute stroke thrombectomy. J Neurointerv Surg 2019;11:190-5. 